\title{
Population-specific sequence and expression differentiation in Europeans
}

\author{
Xueyuan Jiang ${ }^{1}$ and Raquel Assis*,1,2 \\ 1 \\ Huck Institutes of the Life Sciences, Pennsylvania State University, University Park, PA 16802 \\ 2 \\ Department of Biology, Pennsylvania State University, University Park, PA 16802 \\ *Corresponding author. Email: rassis@psu.edu
}

\begin{abstract}
Much of the enormous phenotypic variation observed across human populations is thought to have arisen from events experienced as our ancestors peopled different regions of the world. However, little is known about the genes involved in these population-specific adaptations. Here we explore this problem by simultaneously examining populationspecific sequence and expression differentiation in four human populations. In particular, we design a branch-based statistic to estimate population-specific differentiation in four populations, and apply this statistic to single nucleotide polymorphism (SNP) and RNAseq data from Italian, British, Finish, and Yoruban populations. As expected, genome-wide estimates of sequence and expression differentiation each independently recapitulate the known demographic history of these four human populations, highlighting the utility of our statistic for identifying genic targets of population-specific adaptations. Application of our statistic reveals that genes containing large copy number variations (CNVs) have elevated levels of population-specific sequence and expression differentiation, consistent with the hypothesis that gene turnover is a key reservoir of adaptive variation. Further, European genes displaying population-specific sequence and expression differentiation are enriched for functions related to epigenetic regulation, immunity, and reproduction. Together, our findings illustrate that population-specific sequence and expression differentiation in humans may preferentially target genes with CNVs and play important roles in a diversity of adaptive and disease-related phenotypes.
\end{abstract}

\section{Introduction}

Human phenotypes vary widely across the globe. In particular, geographically separated populations often differ in skin pigmentation (Loomis 1967), hair color (Rees 2003), tooth morphology (Scott and Turner 1997; Hanihara and Ishida 2005), surface area to body mass ratio (Katzmarzyk and Leonard 1998), and predisposition to diseases (Frank 2004). Much of this phenotypic variation is thought to have arisen due to a diversity of selective pressures experienced as early humans peopled the world and encountered novel environments (Sabeti et al. 2002; Voight et al. 2006), food sources (Sabeti et al. 2002), and pathogens (Diamond 2002; Jobling et al. 2013). As a result, uncovering the genetic targets of phenotypic variation among human populations is critical both for understanding past human adaptations (Sabeti et al. 2002) and for advancing future biomedical research (Jorde et al. 2001; Akey et al. 2004).

Due to the abundance of whole-genome sequence and polymorphism data for many human populations (Cann et al. 2002; International HapMap 3 Consortium 2010; The 1000 Genome 
Projects Consortium 2015), much work in the past several years has focused on elucidating and understanding sequence differentiation that occurred during human evolution (Li et al. 2008; Pickrell et al. 2009; Field et al. 2016). A common summary statistic for estimating sequence distances between two populations is the fixation index, $F_{\mathrm{ST}}$ (Wright 1951), which has been used to infer human demographic history (Hinds et al. 2005; Holsinger and Weir 2009; Keinan et al. 2009; Patterson et al. 2012; The 1000 Genome Projects Consortium 2015) and identify loci that may be targets of natural selection (Bowcock et al. 1991; Akey et al. 2002; Bersaglieri et al. 2004). However, because $F_{\mathrm{ST}}$ is a pairwise metric, it cannot identify the directionality of sequence differentiation nor be used as sole evidence for natural selection (Yi et al. 2010). To address this issue, Yi et al. (Yi et al. 2010) developed the Population Branch Statistic (PBS), a summary statistic that utilizes pairwise $F_{\text {ST }}$ values among three populations to quantify sequence differentiation along each branch of their corresponding three-population tree. Genes with large PBS values on one branch represent loci that underwent population-specific sequence differentiation consistent with positive selection (Yi et al. 2010). PBS has been applied to corroborate previously established targets of selection, including genes associated with skin pigmentation (Lamason et al. 2005) and dietary fat sources (Mathias et al. 2012), as well as to identify novel candidates for high-altitude adaptation in Tibetans (Yi et al. 2010).

However, because natural selection acts on phenotypes, analysis of sequence data only enables assessment of its indirect effects. For this reason, it may be advantageous to study selection more directly by exploiting the recent availability of RNA-seq data for several human populations (Lappalainen et al. 2013). Specifically, phenotypic evolution is thought to often occur through modifications in gene expression (King and Wilson 1975; Wang et al. 1996; Wray et al. 2003; Carroll 2005; Carroll 2008; Raj et al. 2010). Thus, studying gene expression differentiation among human populations may increase power for identifying loci underlying population-specific phenotypic variation. Indeed, like genetic differentiation, gene expression levels vary considerably across human populations (Cheung et al. 2005; Stranger et al. 2007) and often reflect population structure (Brown et al. 2018). Moreover, human genes with large PBS values are enriched for expression quantitative trait loci (eQTLs; Quiver and Lachance 2018).

In the present study, we simultaneously explore population-specific sequence and expression differentiation in four human populations: the Toscani in Italia (TSI), British in England and Scotland (GBR), Finnish in Finland (FIN), and Yoruba in Nigeria (YRI). For these analyses, we employ single nucleotide polymorphism (SNP; The 1000 Genome Projects Consortium 2015) and RNA-seq (Lappalainen et al. 2013) data from each population. First, we use $F_{\mathrm{ST}}$ (Wright 1951) and its analogue for estimating quantitative trait differentiation, $P_{\mathrm{ST}}$ (Leinonen et al. 2006), to quantify and examine genome-wide patterns of sequence and expression differentiation in the four human populations. Next, we adapt the approach of PBS (Yi et al. 2010) to $P_{\mathrm{ST}}$, as well as extend its computation to a four-population tree, enabling us to estimate both sequence and expression differentiation in each of the four human populations. Last, we apply these branch-based statistics to study population-specific sequence and expression differentiation in Europeans and uncover candidate genes and functional modules underlying adaptation in TSI, GBR, and FIN populations.

\section{Results}

\subsection{Genome-wide patterns of sequence and expression differentiation in four human populations}

A first goal of our study was to estimate sequence and expression differentiation among TSI, GBR, FIN, and YRI populations. To address this problem, we used SNP data (The 1000 Genome Projects Consortium 2015) to calculate the $F_{\text {ST }}$ (Wright 1951), and RNA-seq data (Lappalainen et al. 2013) 
to calculate the $P_{\mathrm{ST}}$ (Leinonen et al. 2006), of every gene between each pair of the four human populations. We calculated $F_{\mathrm{ST}}$ using Hudson's formula (Hudson et al. 1992) and computed the ratio of averages to minimize bias (Reynolds et al. 1983; Weir and Cockerham 1984; International HapMap 3 Consortium 2010; Bhatia et al. 2013; see Materials and Methods for details). Due to environmental effects on $P_{\mathrm{ST}}$, we followed the approach of Leinonen et al. (2006) in calculating $P_{\text {ST }}$ under two contrasting scenarios: one in which environmental and non-additive genetic effects account for half of the observed expression variation $\left(h^{2}=0.5\right)$, and a second in which only additive genetic effects contribute to the observed expression variation $\left(h^{2}=1\right.$; see Materials and Methods for details). Examinations of Pearson's linear $(r)$ and Spearman's nonlinear $(\rho)$ correlations revealed small but significantly positive relationships between $F_{\mathrm{ST}}$ and $P_{\mathrm{ST}}$ in TSI-FIN, TSI-YRI, GBR-YRI, and FIN-YRI population pairs (Tables S1-S2), consistent with previous observations that sequence and expression differentiation are weakly or moderately associated (Makova and Li 2003; Nuzhdin et al. 2004; Sartor et al. 2006; Hunt et al. 2012; Assis and Bachtrog 2013; Assis and Bachtrog 2015).

To explore genome-wide patterns of sequence and expression differentiation among the four human populations, we independently used $F_{\mathrm{ST}}$ and $P_{\mathrm{ST}}$ to construct gene trees and then infer population trees supported by majorities of these gene trees (see Materials and Methods for details). Population trees obtained from $F_{\mathrm{ST}}$ and $P_{\mathrm{ST}}\left(h^{2}=0.5\right.$ and $\left.h^{2}=1\right)$ have the same topology (Figure 1), indicating that there is consistency between relationships inferred from genome-wide patterns of sequence and expression differentiation despite their weak correlations with one another. Moreover, as expected due to increased noise in gene expression data (Raser and O'Shea 2005), gene trees obtained from $P_{\mathrm{ST}}\left(h^{2}=0.5\right.$ and $\left.h^{2}=1\right)$ are more variable than those derived from $F_{\mathrm{ST}}$. Further, the topology of the population trees recapitulates human demographic history, in that TSI and GBR populations are most closely related to one another, the FIN population is an outgroup to TSI and GBR, and the YRI population is an outgroup to all three European populations. These results mirror those from similar studies of $F_{\mathrm{ST}}$ (Hinds et al. 2005; Holsinger and Weir 2009; Keinan et al. 2009; Patterson et al. 2012; The 1000 Genome Projects Consortium 2015), as well as findings that gene expression data often display population structure comparable to that of sequence data (Cheung et al. 2005; Stranger et al. 2007; Brown et al. 2018).

\subsection{Estimation of population-specific sequence and expression differentiation on a four- population tree}

Next, we sought to quantify population-specific sequence and expression differentiation of genes in each of the four human populations. For a three-population tree, population-specific sequence differentiation of a gene along each branch can be estimated with PBS (Yi et al. 2010) (Figure 2A), which applies Equation 11.20 in Felsenstein (Felenstein 2004) to $F_{\text {ST }}$. In particular, considering the unrooted three-population tree shown in Figure 2A, the PBS value of a particular gene in population $\mathrm{W}$ is estimated as $\mathrm{PBS}_{\mathrm{W}}=\frac{1}{2}\left(E_{\mathrm{W}, \mathrm{X}}+E_{\mathrm{W}, \mathrm{Y}}-E_{\mathrm{X}, \mathrm{Y}}\right)$, where $E_{\mathrm{W}, \mathrm{X}}, E_{\mathrm{W}, \mathrm{Y}}$, and $E_{\mathrm{X}, \mathrm{Y}}$ denote logtransformed $F_{\mathrm{ST}}$ between populations $\mathrm{W}$ and $\mathrm{X}, \mathrm{W}$ and $\mathrm{Y}$, and $\mathrm{X}$ and $\mathrm{Y}$, respectively (Yi et al. 2010; see Materials and Methods for details). In a recent study, Equation 11.20 in Felsenstein (Felenstein 2004) was also applied to expression distances between orthologous genes to estimate branch lengths corresponding to lineage-specific expression divergence on a three-species tree (Assis 2018). Analogously, by substituting $P_{\mathrm{ST}}$ for $F_{\mathrm{ST}}$ in the formula for PBS (Yi et al. 2010), we can obtain the PBS corresponding to gene expression differentiation in population $\mathrm{W}$ on the threepopulation tree. To distinguish between these two PBS in our study, we will refer to the calculation with $F_{\mathrm{ST}}$ as the "sequence PBS", and the calculation with $P_{\mathrm{ST}}$ as the "expression PBS".

To enable quantification of population-specific sequence and expression differentiation in four human populations, we further extended the computation of each PBS to a four-population tree 
(Figure 2B) via application of Equation 12.6 in Felsenstein (Felenstein 2004). Henceforth, we will denote PBS as $\mathrm{PBS}_{3}$ when applied to a three-population tree, and as $\mathrm{PBS}_{4}$ when applied to a fourpopulation tree. In particular, considering the unrooted four-population tree depicted in Figure 2B, the PBS value of a particular gene in population A can be estimated as $\mathrm{PBS}_{4, \mathrm{~W}}=\frac{1}{4}\left(2 E_{\mathrm{W}, \mathrm{X}}+E_{\mathrm{W}, \mathrm{Y}}+\right.$ $E_{\mathrm{W}, \mathrm{Z}}-E_{\mathrm{X}, \mathrm{Y}}-E_{\mathrm{X}, \mathrm{Z}}$ ), where $E_{\mathrm{W}, \mathrm{X}}, E_{\mathrm{W}, \mathrm{Y}}, E_{\mathrm{X}, \mathrm{Y}}$, and $E_{\mathrm{X}, \mathrm{Z}}$ denote log-transformed $F_{\mathrm{ST}}$ or $P_{\mathrm{ST}}$ of the gene between populations $\mathrm{W}$ and $\mathrm{X}, \mathrm{W}$ and $\mathrm{Y}, \mathrm{X}$ and $\mathrm{Y}$, and $\mathrm{X}$ and $\mathrm{Z}$, respectively (see Materials and Methods for details). We used this formula to compute the sequence $\mathrm{PBS}_{4}$ and expression $\mathrm{PBS}_{4}$ score of each gene in TSI, GBR, FIN, and YRI populations (Tables S3-S5).

\subsection{Population-specific sequence and expression differentiation of genes with copy number variations}

Gene duplications and deletions are key contributors to human genetic diversity (Sudmant et al. 2015). Moreover, because they are large-scale mutation events that may impact gene dosage, duplications and deletions have been implicated in numerous human diseases (Sebat et al. 2004; Kumar et al. 2008; Sharp et al. 2008; Weiss et al. 2008), as well as in adaptive events in many diverse species (Kaessmann 2010; Chen et al. 2013). As a result, genes containing copy number variations (CNVs) are thought to be more frequently targeted by natural selection than those without CNVs (Freeman et al. 2006; Nguyen et al. 2006). Indeed, genes with CNVs often display signatures of adaptation (Sudmant et al. 2015), and fixation of duplications and deletions has been associated with natural selection in many species (Freeman et al. 2006; Nguyen et al. 2006; Han et al. 2009b; Jiang and Assis 2017). Therefore, we hypothesized that genes with CNVs would have larger sequence and expression $\mathrm{PBS}_{4}$ values than genes without CNVs.

To test this hypothesis, we compared the distributions of maximum $\mathrm{PBS}_{4}$ values of genes with and without known human CNVs larger than 50bp (Figure 3; MacDonald et al. 2013; see Materials and Methods for details). Consistent with our prediction, both sequence and expression $\mathrm{PBS}_{4}$ values are significantly elevated in genes with CNVs (Figure 3; $P<0.05$ for all pairwise comparisons, twosample permutation tests; see Materials and Methods for details). Therefore, genes containing large CNVs appear to undergo increased population-specific sequence and expression differentiation, supporting the hypothesis that both their sequences and expression patterns may be targeted by natural selection.

\subsection{Relationships of population-specific sequence and expression differentiation to gene function in Europeans}

A natural question that emerges from this analysis is what types of functional modules underlie population-specific sequence and expression differentiation in human populations. In addressing this question, it was important to exclude YRI, as it is an outgroup to the three European populations and therefore contains greater overall population-specific sequence and expression differentiation that is difficult to polarize. Hence, we only considered genes with large $\mathrm{PBS}_{4}$ values in TSI, GBR, and FIN populations for these analyses. To globally assess functional modules contributing to population-specific sequence and expression differentiation in these European populations, we utilized annotation data from the Gene Ontology (GO) Consortium (Ashburner et al. 2000; GO Consortium 2018). In particular, GO terms classify genes by their molecular functions, cellular components, and biological processes (Ashburner et al. 2000; GO Consortium 2018). Therefore, to study relationships of population-specific sequence and expression differentiation to gene functions, we ranked genes by their sequence and expression $\mathrm{PBS}_{4}$ values in each population, performed GO enrichment analysis on ranked lists, and extracted significantly overrepresented GO terms (Tables S6-S14; see Materials and Methods for details). 
First, we examined GO enrichment for sequence $\mathrm{PBS}_{4}$ values in TSI, GBR, and FIN populations (Tables S6-S8). Though the three populations do not share any GO terms, they each show enrichment in terms related to neuronal processes. In TSI, the most enriched GO term is "histone methylation", a process whereby methyl groups are attached to histone proteins. Several other enriched terms are also related to methylation, which is interesting because methylation is often used as a signal for gene activation or silencing (Jones 2012), suggesting that population-specific sequence differentiation is related to epigenetic processes in TSI. Moreover, a few enriched GO terms in TSI are related to dynamics of cell membranes, which are common targets of adaptation (Hamblin and Di Rienzo 2000; Sabeti et al. 2006). In GBR, the most enriched GO term for sequence $\mathrm{PBS}_{4}$ values is "branching involved in labyrinthine layer morphogenesis", a process whereby the branches of fetal placental villi are generated and organized. Therefore, increased populationspecific sequence differentiation in GBR may be related to reproduction and fetal development. This is particularly intriguing because, though natural selection frequently targets reproductive phenotypes, often they are male-specific (Pröschel et al. 2006; Ellegren and Parsch 2007; Assis and Bachtrog 2013; Harrison et al. 2015). Yet this GO term specifically relates to female-specific functions, indicating that population-specific adaptation may be associated with female reproductive phenotypes in GBR. In FIN, the most enriched GO term for sequence $\mathrm{PBS}_{4}$ values is "ncRNA transcription", a process whereby noncoding DNA is transcribed into RNA. Though noncoding RNAs are not translated into proteins, they often play important roles in gene regulation and expression (He and Hannon 2004; Mercer et al. 2009). Also interesting is that many other enriched GO terms in FIN are related to reproduction, and specifically to male gamete generation and spermatogenesis, which are often targets of adaptation ( $\mathrm{Li}$ et al. 2002; Zhou and Bachtrog 2012).

Next, we examined GO enrichment for expression $\mathrm{PBS}_{4}$ values in TSI, GBR, and FIN populations (Tables S9-S14). Using $P_{\mathrm{ST}}$ with $h^{2}=0.5$ and with $h^{2}=1$ yielded similar results, consistent with our expectations based on previous comparisons (see Figures 1 and 2). However, a surprising finding was the abundance of enriched GO terms for expression $\mathrm{PBS}_{4}$ values relative to those for sequence $\mathrm{PBS}_{4}$ values. Perhaps as a result, many enriched GO terms are shared by the three populations: "cell surface receptor signaling pathway", "developmental process", "positive regulation of response to stimulus", "regulation of cell communication", "regulation of immune system process", "regulation of multicellular organismal process", and "signal transduction". Though most of these GO terms are quite general and difficult to interpret, it appears that population-specific expression differentiation in Europeans is often related to processes involved in signal transduction, immunity, reproduction, and development. Moreover, many related GO terms are enriched in Europeans, including those with the most enrichment in each population. The abundance of these GO terms is not surprising, particularly as such processes are frequent targets of natural selection (Barreiro and Quintana-Murci 2010; Fumagalli et al. 2011; Enard et al. 2016).

To glean further insight into specific genes potentially driving population-specific sequence and expression differentiation in Europeans, we performed literature searches on genes with the largest sequence and expression $\mathrm{PBS}_{4}$ values in each population. The gene with the largest sequence $\mathrm{PBS}_{4}$ value in both TSI and GBR is MCM6, or Minichromosome Maintenance Complex Component 6. $M C M 6$ is part of a protein complex essential for the initiation of eukaryotic genome replication (Labib et al. 2000). Moreover, two of its introns contain enhancers of its upstream gene $L C T$, or Lactase, one of which has a mutation that is prevalent in European populations and is thought to confer lactose tolerance in adulthood (Enattah et al. 2002; Troelsen et al. 2003). Consistent with this hypothesis, several genetic studies have identified MCM6 and LCT as targets of recent positive selection in Europeans (Bersaglieri et al. 2004; Voight et al. 2006; Ranciaro et al. 2014; Cheng et al. 2017). Moreover, the gene with the second-largest sequence $\mathrm{PBS}_{4}$ value in GBR is $L C T$. In contrast to the other two European populations, the gene with the largest sequence $\mathrm{PBS}_{4}$ value in 
FIN is NPIPA2, or Nuclear Pore Complex Interacting Protein Family Member A2. NPIPA2 is part of the nuclear pore complex of the cell membrane, which regulates exchange between the nucleus and cytoplasm (Strambio-De-Castillia et al. 2010). Polymorphisms in NPIPA2 are associated with several diverse classes of cancer (Dingerdissen et al. 2017), and its deletion is common in earlyonset colorectal cancer (Perea et al. 2017). Moreover, both the localization of NPIPA2 to the cell membrane and its function in transport across the membrane make it a likely target of natural selection (Tang and Presgraves 2009; Tracy et al. 2010).

The gene with the largest expression $\mathrm{PBS}_{4}$ value (for $P_{\mathrm{ST}}$ with $h^{2}=0.5$ and $h^{2}=1$ ) in TSI is $P R R X 1$, or Paired Related Homeobox 1. PRRX1 is a DNA-associated protein that functions as a transcription coactivator and is involved in the establishment of diverse mesodermal muscle types during embryonic development (Martin et al. 1995). In particular, PRRXI is thought to play a critical role in craniofacial muscle development, as its variants are associated with several diseases that result in facial and neck malformations linked to sleep apnea (Martin et al. 1995; Urbizu et al. 2013). Further, $P R R X 1$ has also been associated with numerous cancers (Takahashi et al. 2013; Guo et al. 2015; Hirata et al. 2015; Jurecekova et al. 2016; Takano et al. 2016; Zhu et al. 2017), and is thought to mediate metastasis, or the migration and invasion of cancer cells into diverse tissues (Ocaña et al. 2012; Takahashi et al. 2013; Guo et al. 2015; Zhu et al. 2017). In GBR, the gene with the largest expression $\mathrm{PBS}_{4}$ value (for $P_{\mathrm{ST}}$ with $h^{2}=0.5$ and $h^{2}=1$ ) is $P R K C B$, or Protein Kinase $\mathrm{C}$ Beta. $P R K C B$ is involved in a diversity of cellular signaling pathway, including $\mathrm{B}$ cell activation during immune response (Lutzny et al. 2013), apoptosis (Reyland 2009), and autophagy (Patergnani et al. 2013). As a result, mutations in PRKCB are associated with numerous common diseases, including several cancers (Lutzny et al. 2013; Wallace et al. 2014; Antal et al. 2015) and autoimmune diseases (Han et al. 2009a; Sheng et al. 2010; Kawashima et al. 2017). The association with autoimmune diseases is particularly intriguing, as such genes are often identified as targets of recent positive selection (Barreiro and Quintana-Murci 2010; Ramos et al. 2014). It is hypothesized that mutations that cause autoimmune response today may have provided pathogen resistance in the past (Barreiro and Quintana-Murci 2010). Last, in FIN, the gene with the highest expression $\mathrm{PBS}_{4}$ value for $P_{\mathrm{ST}}$ with $h^{2}=0.5$ in FIN is $V D R$, or Vitamin D Receptor, whereas the gene with the highest expression $\mathrm{PBS}_{4}$ value for $P_{\mathrm{ST}}$ with $h^{2}=1$ is $P L A C 8$, or Placenta Specific 8. VDR interacts with vitamin $\mathrm{D}$ in the small intestine to facilitate calcium transportation into circulation (Holick 2006), and has been associated with vitamin D-dependent rickets (Holick 2006; Wagner and Greer 2008) and osteoporosis (Holick 2004). Skin exposure to solar ultraviolet radiation (UVR) produces about $90 \%$ of the vitamin D that an individual requires (Holick 2006), and living at high latitudes has been associated with vitamin D deficiency due to decreased UVR (Kimlin 2008; Chaplin and Jablonski 2009). Therefore, it is possible that expression differentiation of VDR may contribute to high latitude adaptation in FIN. PLAC8 is also an interesting candidate, as it was first identified in human dendritic cells (Rissoan et al. 2002) and was later found to be expressed in interstitial extravillous trophoblast cells in the placenta, playing a key role in promoting their invasion and migration (Chang et al. 2018). PLAC8 also facilitates the epithelial-to-mesenchymal transition (EMT) in colon cancer cells ( $\mathrm{Li}$ et al. 2014) and has been associated with autoimmune diseases (Orrù et al. 2013). Therefore, expression differentiation of PLAC8 in FIN may be related to its role in reproduction or disease.

\section{Discussion}

Identifying drivers of human phenotypic variation is crucial to understanding adaptive events that occurred in the past, as well as to developing population- and individual-targeted treatments for diseases in the future (Jorde et al. 2001; Sabeti et al. 2002; Akey et al. 2004). Though previous research (Sabeti et al. 2002; Akey et al. 2004; Voight et al. 2006) has made use of abundant whole- 
genome and polymorphism data for many human populations (International HapMap 3 Consortium 2010; The 1000 Genome Projects Consortium 2015) to answer this question, simultaneously studying sequence and expression differentiation may provide unique insights into direct phenotypic targets of natural selection. In particular, it is thought that phenotypic evolution more often occurs through changes in gene regulation and expression, rather than their protein-coding sequences (King and Wilson 1975; Wang et al. 1996; Wray et al. 2003; Carroll 2005; Carroll 2008; Raj et al. 2010). For this reason, gene expression differentiation might better reflect phenotypic variation. Therefore, a major advantage of the present study is that we utilized from both sequence and expression data to address questions about population-specific differentiation in humans. Further, results from our combined analysis suggest that population-specific sequence and expression differentiation in humans may be attributed to several important biological processes, most notably immunity and reproduction, and also pinpoint many candidate genes for further study of human phenotypic variation in adaptation and disease.

A potential limitation of our study is the usage of RNA-seq data obtained from lymphoblastoid cell lines. In particular, the enrichment of immune-related functions in genes with high levels of population-specific expression differentiation may be attributed to usage of this cell line, rather than reflecting widespread evolutionary patterns of immunity genes across tissues. Yet it is important to note that associations between increased population-specific expression differentiation and immunity are consistent with previous findings. Specifically, immunity genes are among the fastest evolving genes in the human genome, likely due to adaptations to rapidly changing environments and introductions of novel pathogens (Barreiro and Quintana-Murci 2010; Fumagalli et al. 2011; Enard et al. 2016). Therefore, though observed patterns of population-specific expression differentiation may not be representative of those in other cell types, genes with high population-specific expression differentiation should be further studied to examine their potential roles in human evolutionary history and disease. Regardless, future availability of RNA-seq data for multiple cell or tissue types in several populations will be invaluable for capturing complex patterns of population-specific expression differentiation and pinpointing genic targets of phenotypic variation among human populations.

Another caveat of these RNA-seq data (Lappalainen et al. 2013) is that TSI, GBR, and FIN are closely related European populations. Detection of population-specific differentiation is inherently difficult, as strong positive selection is thought to be rare in recent human evolution (Hernandez et al. 2011; The 1000 Genome Projects Consortium 2015). In addition, we expect sequence and expression differentiation to be correlated among these populations due to their shared ancestry and possible gene flow. Moreover, genetic and phenotypic differences among distantly related populations are better described than those among closely related populations, making it difficult to interpret our findings in the context of human phenotypes. Therefore, future availability of RNAseq data from additional populations, particularly those that are more distantly related, will be critical to studying population-specific variation and its role in both human evolution and disease.

Despite the limitations of these data, a major advantage of our study is the design of $\mathrm{PBS}_{4}$, a novel summary statistic that can be used to estimate population-specific sequence or expression differentiation in four populations. In particular, $\mathrm{PBS}_{4}$ requires minimal assumptions about the data and can be used to rapidly estimate population-specific sequence or expression differentiation on a genome-wide scale. Further, because $\mathrm{PBS}_{4}$ utilizes data from four populations, branch lengths are more likely to represent true population-specific differentiation than differentiation that occurred ancestral to two populations, as is possible in a three-population scenario (Assis 2018). Therefore, though the dataset used in our study is not ideal in many respects, $\mathrm{PBS}_{4}$ can easily be applied to existing or future datasets to quantify population-specific sequence or expression differentiation in humans and other species. In particular, we envision that application of $\mathrm{PBS}_{4}$ to future human RNA- 
seq data from multiple cell lines or tissues and in many populations of varying divergence levels will shed light on complex questions about human evolutionary history and disease processes.

\section{Materials and Methods}

\subsection{Population-genetic analyses}

We downloaded the 1000 Genomes Project phase 3 dataset (The 1000 Genome Projects Consortium 2015) for TSI, GBR, FIN, and YRI populations from $\mathrm{ftp} / / / \mathrm{ftp} .1000$ genomes.ebi.ac.uk/vol1/ftp/. After filtering out insertions, deletions, and singlenucleotide polymorphisms with Minor Allele Frequencies (MAF) less than 0.01, we were left with $15,145,123$ SNPs. We calculated Hudson's $F_{\text {ST }}$ for each SNP (Reynolds et al. 1983; Weir and Cockerham 1984; Bhatia et al. 2013). Then, we combined SNPs within the entire annotated region of each gene and computed the "ratio of averages" for Hudson's $F_{\text {ST }}$ (Reynolds et al. 1983; Weir and Cockerham 1984; Bhatia et al. 2013). Because negative $F_{\text {ST }}$ values are not defined (Wright 1951) and have no biological interpretation (Akey et al. 2002), we followed the standard of setting all negative $F_{\text {ST }}$ values to zero (e.g., Nei 1990; Akey et al. 2002).

\subsection{Gene expression analyses}

We obtained RNA-seq data from lymphoblastoid cell lines in TSI, GBR, FIN, and YRI populations from the GEUVADIS project (Lappalainen et al. 2013). We excluded data from the population of Utah Residents with Northern and Western European Ancestry (CEU) because they were collected from an older cell line and display expression patterns that are inconsistent with their demographic history (Yuan et al. 2015). We quantified the abundance of transcripts in the remaining 371 individuals (93 in TSI, 94 in GBR, 95 in FIN, and 89 in YRI) using featureCount (Liao et al. 2013) with the long reads option (-L) and the GRCh37 human genome (Zerbino et al. 2017) as our reference. To normalize count data, we used the "median ratio method" method (Anders and Huber 2010) by implementing the estimateSizeFactors function in DESeq2 (Love et al. 2014). Next, we calculated the Fragments Per Kilobase of transcript per Million mapped reads (FPKM) of each gene using DESeq2 (Love et al. 2014). We removed genes that contained fewer than 10 reads in each sample (lowly-expressed), were located on sex chromosomes, or were not protein-coding. For the remaining 13,075 genes, we log-transformed their FPKM values by $\log (\mathrm{FPKM}+1)$. We computed the $P_{\mathrm{ST}}$ for each gene as $P_{S T}=\frac{\sigma_{\text {between }}^{2}}{\sigma_{\text {between }}^{2}+2 h^{2} \sigma_{\text {within }}^{2}}$ (Leinonen et al. 2006), where $\sigma_{\text {between }}^{2}$ is expression variance between populations, $\sigma_{\text {within }}^{2}$ is expression variance within populations, and $h^{2}$ is heritability. For our analysis, we used $h^{2}=0.5$ and $h^{2}=1$ as was done previously (Leinonen et al. 2006), though we noted that the patterns in Figure 1 do not change as a function of $h^{2}$. When $h^{2}$ $=1, P_{\mathrm{ST}}$ reduces to $Q_{\mathrm{ST}}$ (Spitze 1993), another common metric for differentiation of quantitative traits between populations.

\subsection{Phylogenetic analyses}

To infer population trees, we first built gene trees using the NEIGHBOR program in the PHYLIP package (Felsenstein 1993). We constructed gene trees using either $F_{\mathrm{ST}}$ or $P_{\mathrm{ST}}$ as input distances between populations. Application of the UPGMA algorithm in the NEIGHBOR program yielded totals of 12,977 gene trees for $F_{\mathrm{ST}}$ and 13,075 gene trees for $P_{\mathrm{ST}}$. Next, we used gene trees as input for the CONSENSE program in the PHYLIP package (Felsenstein 1993) and obtained rooted population trees supported by the majority of gene trees based on $F_{\mathrm{ST}}$ and $P_{\mathrm{ST}}$. Specifically, the nodes in gene trees are included if they continue to resolve the population tree and do not contradict with more frequently occurring nodes. The number above each node in Figure 1 therefore represents its occurrence in all gene trees. 


\subsection{Calculation of $\mathrm{PBS}_{4}$}

We first computed the sequence or expression distance between populations as $E_{\mathrm{A}, \mathrm{B}}=-\log (1-$ $Z_{\mathrm{ST}}(\mathrm{A}, \mathrm{B})$ ), following the approach of Cavalli-Sforza (Cavalli-Sforza 1969), where $Z_{\mathrm{ST}}$ represents either $F_{\mathrm{ST}}$ or $P_{\mathrm{ST}}$ between populations A and B. We used these as input for calculations of sequence and expression $\mathrm{PBS}_{4}$ values. Negative branch lengths were set to zero.

\subsection{GO enrichment analyses}

We performed all GO analyses on ranked lists of genes with the GOrilla tool (Eden et al. 2007; Eden et al. 2009). For each run, we output results for all enriched GO categories (process, function, and component) and set the $P$-value threshold to $P=10^{-3}$.

\subsection{Statistical analyses}

All statistical analyses were performed in the R software environment (R Core Team 2013). Twosample permutation tests were used to assess pairwise differences between all groups compared in Figure 3. For each test, we performed 1,000 permutations, using the difference between medians of groups as the test statistic. In particular, we computed the difference between the medians of the two groups for each permutation, and the $P$-value of the permutation test as the proportion of times the absolute value of this difference was greater than or equal to the absolute value of the observed difference in the data. The significance of correlation coefficients shown in Table S1-2 were assessed via Student's $t$ tests.

\section{Acknowledgements}

This work was supported by the National Science Foundation (DEB-1555981). Portions of this research were conducted with Advanced Cyber Infrastructure computational resources provided by the Institute for CyberScience at Pennsylvania State University (https://ics.psu.edu).

\section{Disclosure declaration}

The authors declare no conflict of interests.

\section{References}

Akey JM, Eberle MA, Rieder MJ, Carlson CS, Shriver MD, Nickerson DA, Kruglyak L. 2004. Population history and natural selection shape patterns of genetic variation in 132 genes. PLOS Biol 2: e286.

Akey JM, Zhang G, Zhang K, Jin L, Shriver MD. 2002. Interrogating a high-density SNP map for signatures of natural selection. Genome Res 12: 1805-1814.

Alves-Silva J, da Silva Santos M, Guimarães PE, Ferreira AC, Bandelt H-J, Pena SD, Prado VF. 2000. The ancestry of Brazilian mtDNA lineages. Am J Hum Genet 67: 444-461.

Anders S, Huber W. 2010. Differential expression analysis for sequence count data. Genome Biol 11: R106.

Antal CE, Hudson AM, Kang E, Zanca C, Wirth C, Stephenson NL, Trotter EW, Gallegos LL, Miller CJ, Furnari FB. 2015. Cancer-associated protein kinase C mutations reveal kinase's role as tumor suppressor. Cell 160: 489-502.

Ashburner M, Ball CA, Blake JA, Botstein D, Butler H, Cherry JM, Davis AP, Dolinski K, Dwight SS, Eppig JT. 2000. Gene ontology: tool for the unification of biology. Nature Genet 25: 25-29.

Assis R. 2018. Lineage-specific expression divergence in grasses is associated with male reproduction, host-pathogen defense, and domestication. Genome Biol Evol 11: 207-219. 
Assis R, Bachtrog D. 2013. Neofunctionalization of young duplicate genes in Drosophila. Proc Natl Acad Sci USA 110: 17409-17414.

Assis R, Bachtrog D. 2015. Rapid divergence and diversification of mammalian duplicate gene functions. BMC Evol Biol 15: 138.

Baeuerle PA, Baltimore D. 1996. NF-кB: ten years after. Cell 87: 13-20.

Barreiro LB, Quintana-Murci L. 2010. From evolutionary genetics to human immunology: how selection shapes host defence genes. Nat Rev Genet 11: 17.

Basiri K, Belaya K, Liu WW, Maxwell S, Sedghi M, Beeson D. 2013. Clinical features in a large Iranian family with a limb-girdle congenital myasthenic syndrome due to a mutation in DPAGT1. Neuromuscular Disord 23: 469-472.

Belaya K, Finlayson S, Slater CR, Cossins J, Liu WW, Maxwell S, McGowan SJ, Maslau S, Twigg SR, Walls TJ. 2012. Mutations in DPAGT1 cause a limb-girdle congenital myasthenic syndrome with tubular aggregates. Am J Hum Genet 91: 193-201.

Bernard G, Chouery E, Putorti ML, Tétreault M, Takanohashi A, Carosso G, Clément I, BoespflugTanguy O, Rodriguez D, Delague V. 2011. Mutations of POLR3A encoding a catalytic subunit of RNA polymerase Pol III cause a recessive hypomyelinating leukodystrophy. Am J Hum Genet 89: 415-423.

Bersaglieri T, Sabeti PC, Patterson N, Vanderploeg T, Schaffner SF, Drake JA, Rhodes M, Reich DE, Hirschhorn JN. 2004. Genetic signatures of strong recent positive selection at the lactase gene. Am J Hum Genet 74: 1111-1120.

Bhatia G, Patterson NJ, Sankararaman S, Price AL. 2013. Estimating and interpreting $\mathrm{F}_{\mathrm{ST}}$ : the impact of rare variants. Genome Res 23:1514-1521.

Bowcock AM, Kidd JR, Mountain JL, Hebert JM, Carotenuto L, Kidd KK, Cavalli-Sforza LL. 1991. Drift, admixture, and selection in human evolution: a study with DNA polymorphisms. Proc Natl Acad Sci USA 88: 839-843.

Brown BC, Bray NL, Pachter L. 2018. Expression reflects population structure. PLOS Genet 14: e1007841.

Bryc K, Durand EY, Macpherson JM, Reich D, Mountain JL. 2015. The genetic ancestry of african americans, latinos, and european Americans across the United States. Am J Hum Genet 96: 37-53.

Burstein E, Hoberg JE, Wilkinson AS, Rumble JM, Csomos RA, Komarck CM, Maine GN, Wilkinson JC, Mayo MW, Duckett CS. 2005. COMMD proteins, a novel family of structural and functional homologs of MURR1. J Biol Chem 280: 22222-22232.

Cann HM, De Toma C, Cazes L, Legrand M-F, Morel V, Piouffre L, Bodmer J, Bodmer WF, Bonne-Tamir B, Cambon-Thomsen A. 2002. A human genome diversity cell line panel. Science 296: 261-262.

Cann RL, Stoneking M, Wilson AC. 1987. Mitochondrial DNA and human evolution. Nature 325: 31-36.

Canna SW, de Jesus AA, Gouni S, Brooks SR, Marrero B, Liu Y, DiMattia MA, Zaal KJ, Sanchez GAM, Kim H. 2014. An activating NLRC4 inflammasome mutation causes autoinflammation with recurrent macrophage activation syndrome. Nature Genet 46: 11401146.

Carrera IA, Matthijs G, Perez B, Cerdá CP. 2012. DPAGT1-CDG: Report of a patient with fetal hypokinesia phenotype. American Journal of Medical Genetics Part A 158: 2027-2030.

Carroll SB. 2005. Evolution at two levels: on genes and form. PLOS Biol 3: e245.

Carroll SB. 2008. Evo-devo and an expanding evolutionary synthesis: a genetic theory of morphological evolution. Cell 134: 25-36.

Cavalli-Sforza LL. 1969. Human diversity. In Proc 12th Int Congr Genet, Vol 2, pp. 405-416.

Chang W-L, Liu Y-W, Dang Y-L, Jiang X-X, Xu H, Huang X, Wang Y-L, Wang H, Zhu C, Xue L-Q. 2018. PLAC8, a new marker for human interstitial extravillous trophoblast cells, promotes their invasion and migration. Development dev. 148932. 
Chaplin G, Jablonski NG. 2009. Vitamin D and the evolution of human depigmentation. Am J Phys Anthrop 139: 451-461.

Chen S, Krinsky BH, Long M. 2013. New genes as drivers of phenotypic evolution. Nat Rev Genet 14: 645-660.

Cheng X, Xu C, DeGiorgio M. 2017. Fast and robust detection of ancestral selective sweeps. Mol Ecol 26: 6871-6891.

Cheung VG, Spielman RS, Ewens KG, Weber TM, Morley M, Burdick JT. 2005. Mapping determinants of human gene expression by regional and genome-wide association. Nature 437: 1365-1369.

Chiu Y-H, MacMillan JB, Chen ZJ. 2009. RNA polymerase III detects cytosolic DNA and induces type I interferons through the RIG-I pathway. Cell 138: 576-591.

Cooper MD. 2015. The early history of B cells. Nat Rev Immunol 15: 191-197.

Corach D, Lao O, Bobillo C, van Der Gaag K, Zuniga S, Vermeulen M, Van Duijn K, Goedbloed M, Vallone PM, Parson W. 2010. Inferring continental ancestry of Argentineans from autosomal, Y-chromosomal and mitochondrial DNA. Ann Hum Genet 74: 65-76.

Devchand PR, Keller H, Peters JM, Vazquez M, Gonzalez FJ, Wahli W. 1996. The PPAR $\alpha-$ leukotriene B4 pathway to inflammation control. Nature 384: 39.

Diamond J. 2002. Evolution, consequences and future of plant and animal domestication. Nature 418: 700-707.

Dingerdissen HM, Torcivia-Rodriguez J, Hu Y, Chang T-C, Mazumder R, Kahsay R. 2017. BioMuta and BioXpress: mutation and expression knowledgebases for cancer biomarker discovery. Nucleic Acids Res 46: D1128-D1136.

Dumay-Odelot H, Durrieu-Gaillard S, Da Silva D, Roeder RG, Teichmann M. 2010. Cell growthand differentiation-dependent regulation of RNA polymerase III transcription. Cell Cycle 9: 3711-3723.

Eden E, Lipson D, Yogev S, Yakhini Z. 2007. Discovering motifs in ranked lists of DNA sequences. PLOS Comput Biol 3: e39.

Eden E, Navon R, Steinfeld I, Lipson D, Yakhini Z. 2009. GOrilla: a tool for discovery and visualization of enriched GO terms in ranked gene lists. BMC Bioinformatics 10: 48.

Ellegren H, Parsch J. 2007. The evolution of sex-biased genes and sex-biased gene expression. Nat Rev Genet 8: 689-698.

Enard D, Cai L, Gwennap C, Petrov DA. 2016. Viruses are a dominant driver of protein adaptation in mammals. Elife 5: e12469.

Enattah NS, Sahi T, Savilahti E, Terwilliger JD, Peltonen L, Järvelä I. 2002. Identification of a variant associated with adult-type hypolactasia. Nature Genet 30: 233-237.

Felsenstein J. 1993. PHYLIP (phylogeny inference package), version 3.5 c. Joseph Felsenstein.

Felsenstein J. 2004. Inferring phylogenies. Sinauer associates Sunderland, MA.

Field Y, Boyle EA, Telis N, Gao Z, Gaulton KJ, Golan D, Yengo L, Rocheleau G, Froguel P, McCarthy MI. 2016. Detection of human adaptation during the past 2000 years. Science 354: 760-764.

Ford-Hutchinson A, Bray M, Doig MV, Shipley M, Smith M. 1980. Leukotriene B, a potent chemokinetic and aggregating substance released from polymorphonuclear leukocytes. Nature 286: 264.

Franca MM, Han X, Funari MF, Lerario AM, Nishi MY, Fontenele EG, Domenice S, Jorge AA, Garcia-Galiano D, Elias CF. 2019. Exome sequencing reveals POLR3H gene as a novel cause of Primary Ovarian Insufficiency. J Clin Endocrinol Metab.

Frank SA. 2004. Genetic predisposition to cancer-insights from population genetics. Nat Rev Genet 5: 764-772.

Freeman JL, Perry GH, Feuk L, Redon R, McCarroll SA, Altshuler DM, Aburatani H, Jones KW, Tyler-Smith C, Hurles ME. 2006. Copy number variation: new insights in genome diversity. Genome Res 16: 949-961. 
Fumagalli M, Sironi M, Pozzoli U, Ferrer-Admettla A, Pattini L, Nielsen R. 2011. Signatures of environmental genetic adaptation pinpoint pathogens as the main selective pressure through human evolution. PLOS Genet 7: e1002355.

GO Consortium. 2018. The Gene Ontology resource: 20 years and still GOing strong. Nucleic Acids Res 47: D330-D338.

Guo J, Fu Z, Wei J, Lu W, Feng J, Zhang S. 2015. PRRX1 promotes epithelial-mesenchymal transition through the Wnt/ $\beta$-catenin pathway in gastric cancer. Med Oncol 32: 393.

Hamblin MT, Di Rienzo A. 2000. Detection of the signature of natural selection in humans: evidence from the Duffy blood group locus. Am J Hum Genet 66: 1669-1679.

Han J-W, Zheng H-F, Cui Y, Sun L-D, Ye D-Q, Hu Z, Xu J-H, Cai Z-M, Huang W, Zhao G-P. 2009a. Genome-wide association study in a Chinese Han population identifies nine new susceptibility loci for systemic lupus erythematosus. Nature Genet 41: 1234-1237.

Han MV, Demuth JP, McGrath CL, Casola C, Hahn MW. 2009b. Adaptive evolution of young gene duplicates in mammals. Genome Res 19: 859-867.

Hanihara T, Ishida H. 2005. Metric dental variation of major human populations. Am J Phys Anthrop 128: 287-298.

Harrison PW, Wright AE, Zimmer F, Dean R, Montgomery SH, Pointer MA, Mank JE. 2015. Sexual selection drives evolution and rapid turnover of male gene expression. Proc Natl Acad Sci USA 112: 4393-4398.

Hayden MS, Ghosh S. 2004. Signaling to NF-кB. Genes Del 18: 2195-2224.

He L, Hannon GJ. 2004. MicroRNAs: small RNAs with a big role in gene regulation. Nat Rev Genet 5: 522-531.

Heifetz A, Elbein AD. 1977. Solubilization and properties of mannose and N-acetylglucosamine transferases involved in formation of polyprenyl-sugar intermediates. $J$ Biol Chem 252: 3057-3063.

Hernandez RD, Kelley JL, Elyashiv E, Melton SC, Auton A, McVean G, Sella G, Przeworski M. 2011. Classic selective sweeps were rare in recent human evolution. Science 331: 920-924.

Hinds DA, Stuve LL, Nilsen GB, Halperin E, Eskin E, Ballinger DG, Frazer KA, Cox DR. 2005. Whole-genome patterns of common DNA variation in three human populations. Science 307: 1072-1079.

Hirata H, Sugimachi K, Takahashi Y, Ueda M, Sakimura S, Uchi R, Kurashige J, Takano Y, Nanbara S, Komatsu H. 2015. Downregulation of PRRX1 confers cancer stem cell-like properties and predicts poor prognosis in hepatocellular carcinoma. Ann Surg Oncol 22: 1402-1409.

Holick MF. 2004. Vitamin D: importance in the prevention of cancers, type 1 diabetes, heart disease, and osteoporosis. Am J Clin Nutr 79: 362-371.

Holick MF. 2006. Resurrection of vitamin D deficiency and rickets. J Clin Invest 116: 2062-2072.

Holsinger KE, Weir BS. 2009. Genetics in geographically structured populations: defining, estimating and interpreting $\mathrm{F}_{\text {ST. Nat Rev Genet 10: 639-650. }}$

Hu B, Elinav E, Huber S, Booth CJ, Strowig T, Jin C, Eisenbarth SC, Flavell RA. 2010. Inflammation-induced tumorigenesis in the colon is regulated by caspase-1 and NLRC4. Proc Natl Acad Sci USA 107: 21635-21640.

Hudson RR, Slatkin M, Maddison W. 1992. Estimation of levels of gene flow from DNA sequence data. Genetics 132: 583-589.

Hunt BG, Ometto L, Keller L, Goodisman MA. 2012. Evolution at two levels in fire ants: the relationship between patterns of gene expression and protein sequence evolution. Mol Biol Evol 30: 263-271.

International HapMap 3 Consortium. 2010. Integrating common and rare genetic variation in diverse human populations. Nature 467: 52-58.

Iqbal Z, Shahzad M, Vissers LE, Van Scherpenzeel M, Gilissen C, Razzaq A, Zahoor MY, Khan SN, Kleefstra T, Veltman JA. 2013. A compound heterozygous mutation in DPAGT1 
results in a congenital disorder of glycosylation with a relatively mild phenotype. Eur $\mathbf{J}$ Hum Genet 21: 844-849.

Jiang X, Assis R. 2017. Natural selection drives rapid functional evolution of young Drosophila duplicate genes. Mol Biol Evol 34:3089-3098.

Jobling M, Hurles M, Tyler-Smith C. 2013. Human evolutionary genetics: origins, peoples \& disease. Garland Science.

Jones PA. 2012. Functions of DNA methylation: islands, start sites, gene bodies and beyond. Nat Rev Genet 13: 484-492.

Jorde L, Watkins WS, Bamshad M. 2001. Population genomics: a bridge from evolutionary history to genetic medicine. Hum Mol Genet 10: 2199-2207.

Jurecekova J, Grendár M, Babušíková E, Kliment J, Dobrota D, Halašová E. 2016. Genome-wide association study of prostate cancer in population of Slovak men. European Urology Supplements 15: e1343-e1344.

Kaessmann H. 2010. Origins, evolution, and phenotypic impact of new genes. Genome Res 20: 1313-1326.

Katzmarzyk PT, Leonard WR. 1998. Climatic influences on human body size and proportions: ecological adaptations and secular trends. Am J Phys Anthrop 106: 483-503.

Kawashima M, Hitomi Y, Aiba Y, Nishida N, Kojima K, Kawai Y, Nakamura H, Tanaka A, Zeniya M, Hashimoto E. 2017. Genome-wide association studies identify PRKCB as a novel genetic susceptibility locus for primary biliary cholangitis in the Japanese population. Hum Mol Genet 26: 650-659.

Keinan A, Mullikin JC, Patterson N, Reich D. 2009. Accelerated genetic drift on chromosome X during the human dispersal out of Africa. Nature Genet 41: 66-70.

Kimlin MG. 2008. Geographic location and vitamin D synthesis. Mol Aspects Med 29: 453-461.

King M-C, Wilson AC. 1975. Evolution at two levels in humans and chimpanzees. Science 188: 107-116.

Kumar A, Kumar J, Gadodia A, Chumber S, Aggarwal L. 2008. Multiple short-segment colonic duplications. Pediatr Radiol 38: 567-570.

Labib K, Tercero JA, Diffley JF. 2000. Uninterrupted MCM2-7 function required for DNA replication fork progression. Science 288: 1643-1647.

Lamason RL, Mohideen M-AP, Mest JR, Wong AC, Norton HL, Aros MC, Jurynec MJ, Mao X, Humphreville VR, Humbert JE. 2005. SLC24A5, a putative cation exchanger, affects pigmentation in zebrafish and humans. Science 310: 1782-1786.

Lappalainen T, Sammeth M, Friedländer MR, AC`t Hoen P, Monlong J, Rivas MA, GonzalezPorta M, Kurbatova N, Griebel T, Ferreira PG. 2013. Transcriptome and genome sequencing uncovers functional variation in humans. Nature 501: 506-511.

Lauberth SM, Nakayama T, Wu X, Ferris AL, Tang Z, Hughes SH, Roeder RG. 2013. H3K4me3 interactions with TAF3 regulate preinitiation complex assembly and selective gene activation. Cell 152: 1021-1036.

Lehrman MA. 1991. Biosynthesis of N-acetylglucosamine-PP-dolichol, the committed step of asparagine-linked oligosaccharide assembly. Glycobiology 1: 553-562.

Leinonen T, Cano J, Mäkinen H, Merilä J. 2006. Contrasting patterns of body shape and neutral genetic divergence in marine and lake populations of threespine sticklebacks. J Evol Biol 19: 1803-1812.

Li C, Ma H, Wang Y, Cao Z, Graves-Deal R, Powell AE, Starchenko A, Ayers GD, Washington MK, Kamath V. 2014. Excess PLAC8 promotes an unconventional ERK2-dependent EMT in colon cancer. $J$ Clin Invest 124: 2172-2187.

Li JZ, Absher DM, Tang H, Southwick AM, Casto AM, Ramachandran S, Cann HM, Barsh GS, Feldman M, Cavalli-Sforza LL. 2008. Worldwide human relationships inferred from genome-wide patterns of variation. Science 319: 1100-1104.

Li W-H, Yi S, Makova K. 2002. Male-driven evolution. Curr Opin Genet Dev 12: 650-656. 
Liang W, Ouyang S, Shaw N, Joachimiak A, Zhang R, Liu Z-J. 2011. Conversion of D-ribulose 5phosphate to D-xylulose 5-phosphate: new insights from structural and biochemical studies on human RPE. The FASEB Journal 25: 497-504.

Liao Y, Smyth GK, Shi W. 2013. featureCounts: an efficient general purpose program for assigning sequence reads to genomic features. Bioinformatics 30: 923-930.

Liu YF, Swart M, Ke Y, Ly K, McDonald FJ. 2013. Functional interaction of COMMD3 and COMMD9 with the epithelial sodium channel. Am J Physiol Renal Physiol 305: F80-F89.

Loomis WF. 1967. Skin-Pigment Regulation of Vitamin-D Biosynthesis in Man: Variation in solar ultraviolet at different latitudes may have caused racial differentiation in man. Science 157: 501-506.

Love MI, Huber W, Anders S. 2014. Moderated estimation of fold change and dispersion for RNAseq data with DESeq2. Genome Biol 15: 550.

Lutzny G, Kocher T, Schmidt-Supprian M, Rudelius M, Klein-Hitpass L, Finch AJ, Dürig J, Wagner M, Haferlach C, Kohlmann A. 2013. Protein kinase c- $\beta$-dependent activation of $\mathrm{NF}-\kappa \mathrm{B}$ in stromal cells is indispensable for the survival of chronic lymphocytic leukemia B cells in vivo. Cancer Cell 23: 77-92.

MacDonald JR, Ziman R, Yuen RK, Feuk L, Scherer SW. 2013. The Database of Genomic Variants: a curated collection of structural variation in the human genome. Nucleic Acids Res 42: D986-D992.

Makova KD, Li W-H. 2003. Divergence in the spatial pattern of gene expression between human duplicate genes. Genome Res 13: 1638-1645.

Malhotra JD, Kaufman RJ. 2011. ER stress and its functional link to mitochondria: role in cell survival and death. Cold Spring Harb Perspect Biol 3: a004424.

Marques AC, Dupanloup I, Vinckenbosch N, Reymond A, Kaessmann H. 2005. Emergence of young human genes after a burst of retroposition in primates. PLOS Biol 3: e357.

Martin JF, Bradley A, Olson EN. 1995. The paired-like homeo box gene MHox is required for early events of skeletogenesis in multiple lineages. Genes Del 9: 1237-1249.

Mathias RA, Fu W, Akey JM, Ainsworth HC, Torgerson DG, Ruczinski I, Sergeant S, Barnes KC, Chilton FH. 2012. Adaptive evolution of the FADS gene cluster within Africa. PLOS ONE 7: e44926.

McDonald MJ, Rice DP, Desai MM. 2016. Sex speeds adaptation by altering the dynamics of molecular evolution. Nature 531: 233-236.

Mercer TR, Dinger ME, Mattick JS. 2009. Long non-coding RNAs: insights into functions. Nat Rev Genet 10: 155-159.

Miao EA, Alpuche-Aranda CM, Dors M, Clark AE, Bader MW, Miller SI, Aderem A. 2006. Cytoplasmic flagellin activates caspase- 1 and secretion of interleukin $1 \beta$ via Ipaf. Nature Immunol 7: 569-575.

Miao EA, Mao DP, Yudkovsky N, Bonneau R, Lorang CG, Warren SE, Leaf IA, Aderem A. 2010. Innate immune detection of the type III secretion apparatus through the NLRC4 inflammasome. Proc Natl Acad Sci USA 107: 3076-3080.

Montenegro G, Rebelo AP, Connell J, Allison R, Babalini C, D'Aloia M, Montieri P, Schüle R, Ishiura H, Price J. 2012. Mutations in the ER-shaping protein reticulon 2 cause the axondegenerative disorder hereditary spastic paraplegia type 12. J Clin Invest 122: 538-544.

Nguyen D-Q, Webber C, Ponting CP. 2006. Bias of selection on human copy-number variants. PLOS Genet 2: e20.

Nuzhdin SV, Wayne ML, Harmon KL, McIntyre LM. 2004. Common pattern of evolution of gene expression level and protein sequence in Drosophila. Mol Biol Evol 21: 1308-1317.

Ocaña OH, Córcoles R, Fabra Á, Moreno-Bueno G, Acloque H, Vega S, Barrallo-Gimeno A, Cano A, Nieto MA. 2012. Metastatic colonization requires the repression of the epithelialmesenchymal transition inducer Prrx1. Cancer cell 22: 709-724. 
Olivo PD, Van de Walle MJ, Laipis PJ, Hauswirth WW. 1983. Nucleotide sequence evidence for rapid genotypic shifts in the bovine mitochondrial DNA D-loop. Nature 306: 400-402.

Orrù V, Steri M, Sole G, Sidore C, Virdis F, Dei M, Lai S, Zoledziewska M, Busonero F, Mulas A. 2013. Genetic variants regulating immune cell levels in health and disease. Cell 155: 242-256.

Patergnani S, Marchi S, Rimessi A, Bonora M, Giorgi C, Mehta KD, Pinton P. 2013. $\mathrm{PRKCB}$ /protein kinase $\mathrm{C}$, beta and the mitochondrial axis as key regulators of autophagy. Autophagy 9: 1367-1385.

Patterson NJ, Moorjani P, Luo Y, Mallick S, Rohland N, Zhan Y, Genschoreck T, Webster T, Reich D. 2012. Ancient admixture in human history. Genetics 192:1065-1093.

Perea J, García JL, Pérez J, Rueda D, Arriba M, Rodríguez Y, Urioste M, González-Sarmiento R. 2017. NOMO-1 gene is deleted in early-onset colorectal cancer. Oncotarget 8: 2442924436.

Pickrell JK, Coop G, Novembre J, Kudaravalli S, Li JZ, Absher D, Srinivasan BS, Barsh GS, Myers RM, Feldman MW. 2009. Signals of recent positive selection in a worldwide sample of human populations. Genome Res 19: 826-837.

Pröschel M, Zhang Z, Parsch J. 2006. Widespread adaptive evolution of Drosophila genes with sex-biased expression. Genetics 174: 893-900.

Quiver MH, Lachance J. 2018. Adaptive eQTLs reveal the evolutionary impacts of pleiotropy and tissue-specificity, while contributing to health and disease in human populations. BioRxiv: 444737

R Core Team. 2013. R: A language and environment for statistical computing. R Foundation for Statistical Computing, Vienna, Austria. 2013.

Raj A, Rifkin SA, Andersen E, Van Oudenaarden A. 2010. Variability in gene expression underlies incomplete penetrance. Nature 463: 913-918.

Ramos PS, Shaftman SR, Ward RC, Langefeld CD. 2014. Genes associated with SLE are targets of recent positive selection. Autoimmune Dis 2014.

Ranciaro A, Campbell MC, Hirbo JB, Ko W-Y, Froment A, Anagnostou P, Kotze MJ, Ibrahim M, Nyambo T, Omar SA. 2014. Genetic origins of lactase persistence and the spread of pastoralism in Africa. Am J Hum Genet 94: 496-510.

Raser JM, O'Shea EK. 2005. Noise in gene expression: origins, consequences, and control. Science 309:2010-2013.

Rees JL. 2003. Genetics of hair and skin color. Annals Rev Genet 37: 67-90.

Reyland ME. 2009. Protein kinase C isoforms: multi-functional regulators of cell life and death. Front Biosci (Landmark Ed) 14: 2386-2399.

Reynolds J, Weir BS, Cockerham CC. 1983. Estimation of the coancestry coefficient: basis for a short-term genetic distance. Genetics 105: 767-779.

Rissoan M-C, Duhen T, Bridon J-M, Bendriss-Vermare N, Péronne C, de Saint Vis B, Briere F, Bates EE. 2002. Subtractive hybridization reveals the expression of immunoglobulinlike transcript 7, Eph-B1, granzyme B, and 3 novel transcripts in human plasmacytoid dendritic cells. Blood 100: 3295-3303.

Roebroek AJ, Contreras B, Pauli IG, Van de Ven WJ. 1998. cDNA Cloning, Genomic Organization, and Expression of the HumanRTN2Gene, a Member of a Gene Family Encoding Reticulons. Genomics 51: 98-106.

Romberg N, Al Moussawi K, Nelson-Williams C, Stiegler AL, Loring E, Choi M, Overton J, Meffre E, Khokha MK, Huttner AJ. 2014. Mutation of NLRC4 causes a syndrome of enterocolitis and autoinflammation. Nature Genet 46: 1135-1139.

Sabeti PC, Reich DE, Higgins JM, Levine HZ, Richter DJ, Schaffner SF, Gabriel SB, Platko JV, Patterson NJ, McDonald GJ. 2002. Detecting recent positive selection in the human genome from haplotype structure. Nature 419: 832-837. 
Sabeti PC, Schaffner SF, Fry B, Lohmueller J, Varilly P, Shamovsky O, Palma A, Mikkelsen T, Altshuler D, Lander E. 2006. Positive natural selection in the human lineage. Science 312: 1614-1620.

Sartor MA, Zorn AM, Schwanekamp JA, Halbleib D, Karyala S, Howell ML, Dean GE, Medvedovic M, Tomlinson CR. 2006. A new method to remove hybridization bias for interspecies comparison of global gene expression profiles uncovers an association between mRNA sequence divergence and differential gene expression in Xenopus. Nucleic Acids Res 34: 185-200.

Scott GR, Turner CG. 1997. Anthropology of modern human teeth. Cambridge University Press Cambridge.

Sebat J, Lakshmi B, Troge J, Alexander J, Young J, Lundin P, Månér S, Massa H, Walker M, Chi M. 2004. Large-scale copy number polymorphism in the human genome. Science 305: 525528.

Selcen D, Shen X-M, Brengman J, Li Y, Stans AA, Wieben E, Engel AG. 2014. DPAGT1 myasthenia and myopathy: genetic, phenotypic, and expression studies. Neurology 82: 1822-1830.

Sharp AJ, Mefford HC, Li K, Baker C, Skinner C, Stevenson RE, Schroer RJ, Novara F, De Gregori M, Ciccone R. 2008. A recurrent 15q13. 3 microdeletion syndrome associated with mental retardation and seizures. Nature Genet 40: 322-328.

Sheng Y-J, Gao J-P, Li J, Han J-W, Xu Q, Hu W-L, Pan T-M, Cheng Y-L, Yu Z-Y, Ni C. 2010. Follow-up study identifies two novel susceptibility loci PRKCB and 8p11.21 for systemic lupus erythematosus. Rheumatology 50: 682-688.

Spitze K. 1993. Population structure in Daphnia obtusa: quantitative genetic and allozymic variation. Genetics 135: 367-374.

Strambio-De-Castillia C, Niepel M, Rout MP. 2010. The nuclear pore complex: bridging nuclear transport and gene regulation. Nat Rev Mol Cell Biol 11: 490-501.

Stranger BE, Nica AC, Forrest MS, Dimas A, Bird CP, Beazley C, Ingle CE, Dunning M, Flicek P, Koller D. 2007. Population genomics of human gene expression. Nature Genet 39: 1217.

Sudmant PH, Mallick S, Nelson BJ, Hormozdiari F, Krumm N, Huddleston J, Coe BP, Baker C, Nordenfelt S, Bamshad M. 2015. Global diversity, population stratification, and selection of human copy-number variation. Science 349: aab3761.

Takahashi Y, Sawada G, Kurashige J, Uchi R, Matsumura T, Ueo H, Takano Y, Akiyoshi S, Eguchi H, Sudo T. 2013. Paired related homoeobox 1, a new EMT inducer, is involved in metastasis and poor prognosis in colorectal cancer. Br J Cancer 109: 307-311.

Takano S, Reichert M, Bakir B, Das KK, Nishida T, Miyazaki M, Heeg S, Collins MA, Marchand B, Hicks PD. 2016. Prrx1 isoform switching regulates pancreatic cancer invasion and metastatic colonization. Genes Del 30: 233-247.

Tang S, Presgraves DC. 2009. Evolution of the Drosophila nuclear pore complex results in multiple hybrid incompatibilities. Science 323: 779-782.

The 1000 Genomes Projects Consortium. 2015. A global reference for human genetic variation. Nature 526: 68-74.

Tracy C, Río J, Motiwale M, Christensen SM, Betrán E. 2010. Convergently recruited nuclear transport retrogenes are male biased in expression and evolving under positive selection in Drosophila. Genetics 184: 1067-1076.

Troelsen JT, Olsen J, Møller J, SjÖstrÖm H. 2003. An upstream polymorphism associated with lactase persistence has increased enhancer activity. Gastroenterology 125: 1686-1694.

Urbizu A, Toma C, Poca MA, Sahuquillo J, Cuenca-Leon E, Cormand B, Macaya A. 2013. Chiari malformation type I: a case-control association study of 58 developmental genes. PLOS ONE 8: e57241.

Voight BF, Kudaravalli S, Wen X, Pritchard JK. 2006. A map of recent positive selection in the human genome. PLOS Biol 4: e72. 
Wagner CL, Greer FR. 2008. Prevention of rickets and vitamin D deficiency in infants, children, and adolescents. Pediatrics 122: 1142-1152.

Wallace JA, Pitarresi JR, Sharma N, Palettas M, Cuitiño MC, Sizemore ST, Yu L, Sanderlin A, Rosol TJ, Mehta KD. 2014. Protein kinase C Beta in the tumor microenvironment promotes mammary tumorigenesis. Front Oncol 4: 87.

Wang D, Marsh JL, Ayala FJ. 1996. Evolutionary changes in the expression pattern of a developmentally essential gene in three Drosophila species. Proc Natl Acad Sci USA 93: $7103-7107$.

Weir BS, Cockerham CC. 1984. Estimating F-statistics for the analysis of population structure. Evolution 38: 1358-1370.

Weiss LA, Shen Y, Korn JM, Arking DE, Miller DT, Fossdal R, Saemundsen E, Stefansson H, Ferreira MA, Green T. 2008. Association between microdeletion and microduplication at 16p11. 2 and autism. N Engl J Med 358: 667-675.

White RJ. 2005. RNA polymerases I and III, growth control and cancer. Nat Rev Mol Cell Biol 6: 69.

Wilson AC, Cann RL, Carr SM, George M, Gyllensten UB, Helm-Bychowski KM, Higuchi RG, Palumbi SR, Prager EM, Sage RD. 1985. Mitochondrial DNA and two perspectives on evolutionary genetics. Biol J Linn Soc Lond 26: 375-400.

Wray GA, Hahn MW, Abouheif E, Balhoff JP, Pizer M, Rockman MV, Romano LA. 2003. The evolution of transcriptional regulation in eukaryotes. Mol Biol Evol 20: 1377-1419.

Wright S. 1951. The genetical structure of populations. Vol 15, pp. 323-354, Annu. Eugenics.

Wu X, Rush JS, Karaoglu D, Krasnewich D, Lubinsky MS, Waechter CJ, Gilmore R, Freeze HH. 2003. Deficiency of UDP-GlcNAc: dolichol phosphate N-acetylglucosamine-1 phosphate transferase (DPAGT1) causes a novel congenital disorder of glycosylation type $\mathrm{Ij}$. Hum Mutat 22: 144-150.

Würde AE, Reunert J, Rust S, Hertzberg C, Haverkämper S, Nürnberg G, Nürnberg P, Lehle L, Rossi R, Marquardt T. 2012. Congenital disorder of glycosylation type Ij (CDG-Ij, DPAGT1-CDG): extending the clinical and molecular spectrum of a rare disease. $\mathrm{Mol}$ Genet Metab 105: 634-641.

Yi X, Liang Y, Huerta-Sanchez E, Jin X, Cuo ZXP, Pool JE, Xu X, Jiang H, Vinckenbosch N, Korneliussen TS. 2010. Sequencing of 50 human exomes reveals adaptation to high altitude. Science 329: 75-78.

Yuan Y, Tian L, Lu D, Xu S. 2015. Analysis of genome-wide RNA-sequencing data suggests age of the CEPH/Utah (CEU) lymphoblastoid cell lines systematically biases gene expression profiles. Sci Rep 5: 7960.

Zerbino DR, Achuthan P, Akanni W, Amode MR, Barrell D, Bhai J, Billis K, Cummins C, Gall A, Girón CG. 2017. Ensembl 2018. Nucleic Acids Res 46: D754-D761.

Zhao Y, Yang J, Shi J, Gong Y-N, Lu Q, Xu H, Liu L, Shao F. 2011. The NLRC4 inflammasome receptors for bacterial flagellin and type III secretion apparatus. Nature 477: 596-600.

Zhou Q, Bachtrog D. 2012. Sex-specific adaptation drives early sex chromosome evolution in Drosophila. Science 337: 341-345.

Zhu H, Sun G, Dong J, Fei L. 2017. The role of PRRX1 in the apoptosis of A549 cells induced by cisplatin. Am J Transl Res 9: 396-402.

Zurek N, Sparks L, Voeltz G. 2011. Reticulon short hairpin transmembrane domains are used to shape ER tubules. Traffic 12: 28-41. 
A

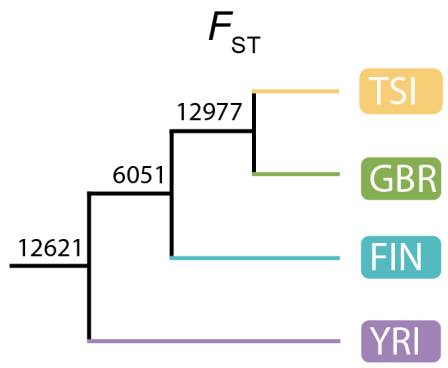

B

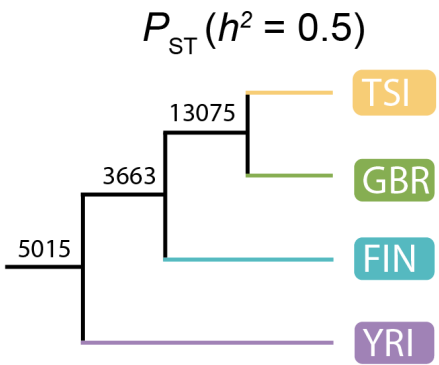

C

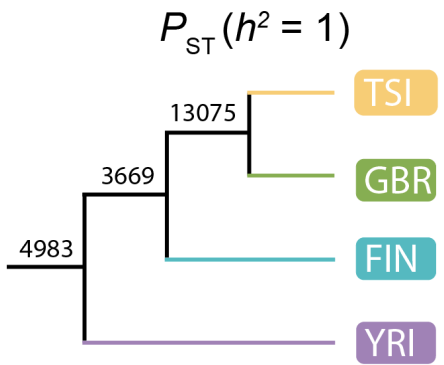

Figure 1. Relationships among TSI, GBR, FIN, and YRI populations inferred from genomewide patterns of sequence and expression differentiation. Population trees supported by the majority of gene trees built using $(A) F_{\mathrm{ST}},(B) P_{\mathrm{ST}}$ with $h^{2}=0.5$, and $(C) P_{\mathrm{ST}}$ with $h^{2}=1$. Numbers indicate occurrences of corresponding nodes in all gene trees (see Materials and Methods for details). 
A
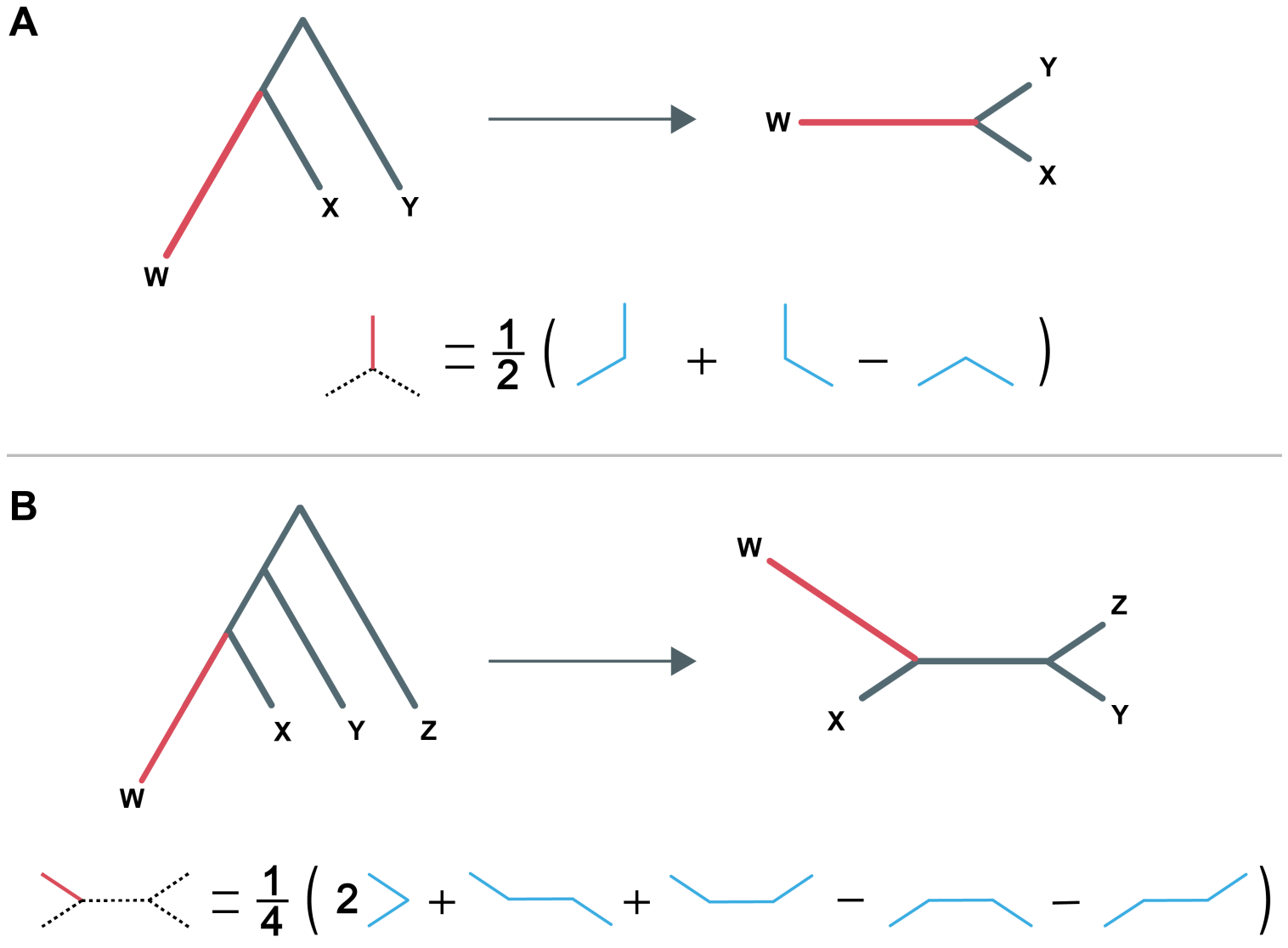

Figure 2. Schematic of PBS calculations. (A) Application of $\mathrm{PBS}_{3}$ to population $\mathrm{W}$ in a tree relating populations $\mathrm{W}, \mathrm{X}$, and $\mathrm{Y}$. The rooted three-population tree is unrooted (top), and the length of branch $\mathrm{W}$ is computed by applying the formula shown (bottom) to pairwise sequence $\left(F_{\mathrm{ST}}\right)$ or expression $\left(P_{\mathrm{ST}}\right)$ distances between populations. $(B)$ Application of $\mathrm{PBS}_{4}$ to population $\mathrm{W}$ in a tree relating populations $\mathrm{W}, \mathrm{X}, \mathrm{Y}$, and $\mathrm{Z}$. The rooted four-population tree is unrooted (top), and the length of branch $\mathrm{W}$ is computed by applying the formula shown (bottom) to pairwise sequence $\left(F_{\mathrm{ST}}\right)$ or expression $\left(P_{\mathrm{ST}}\right)$ distances between populations. 
A

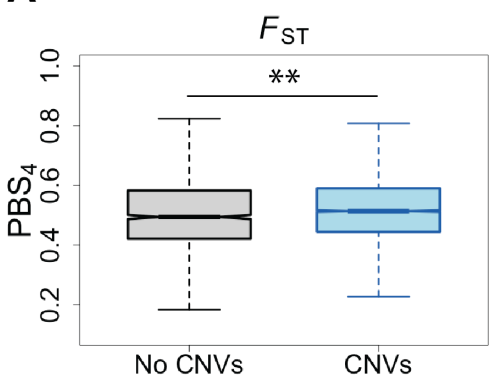

B

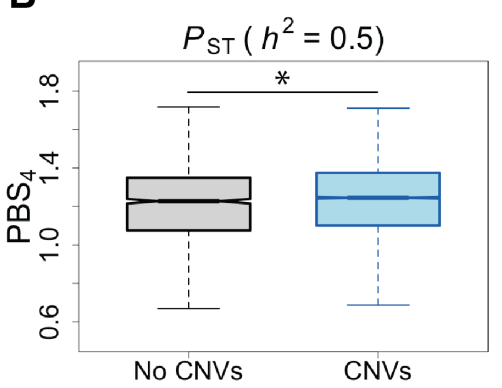

C

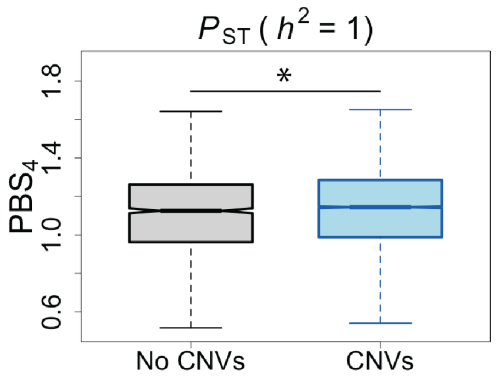

Figure 3. $\mathrm{PBS}_{4}$ values of genes with and without CNVs. Distributions of cube root transformed $(A)$ sequence $\mathrm{PBS}_{4}$ values, $(B)$ expression $\mathrm{PBS}_{4}$ values with $h^{2}=0.5$, and $(C)$ expression $\mathrm{PBS}_{4}$ values with $h^{2}=1$ of genes with (blue) and without (gray) CNVs. $* P<0.05, * * P<0.001$. (See Materials and Methods for details). 